\title{
NiCoP Nanoparticles as Efficient Electrocatalyst for Oxygen Evolution Reaction in an Alkaline Solution
}

\author{
Yuhao Li*, Yanping Tian, Yuhua Yan, Haizhou Chang, Ruizhuo Ouyang and Yuqing Miao* \\ University of Shanghai for Science and Technology, Shanghai 200093, P. R. China. \\ *E-mail: yhli@usst.edu.cn, yqmiao@usst.edu.cn
}

doi: $10.20964 / 2016.12 .21$

Received: 19 August 2016 / Accepted: 26 September 2016 / Published: 10 November 2016

\begin{abstract}
Water splitting can acquire clean energy. To enhance the water splitting ability, electrocatalysts qualify high catalytic ability and low cost are need to be explored. Herein, a bimetal phosphide (NiCoP) nanomaterial is reported as an efficient electrocatalyst for water oxidation. The ternary nickel cobalt phosphide nanoparticles were synthesized from the solution-phase reaction of organic $\mathrm{Co}$ and $\mathrm{Ni}$ precursors with trioctylphosphine. The nanoparticle size is $18 \pm 5 \mathrm{~nm}$. After annealing, the catalytic ability of NiCoP is significantly enhanced. The overpotential decreased from 480 to $330 \mathrm{mV}$ vs RHE at $10 \mathrm{~mA} \mathrm{~cm}^{-2}$ in $1 \mathrm{~mol} \mathrm{dm}^{-3} \mathrm{KOH}$ alkaline solution. When hydrophilic carbon nanotubes (CNTs) mixed with the NiCoP to form hybrid NiCoP-CNTs, the overpential further decreased from 330 to 320 $\mathrm{mV}$ vs RHE at $10 \mathrm{~mA} \mathrm{~cm}^{-2}$. The Tafel slopes of ca. 69 and $52 \mathrm{mV}$ are found for annealed NiCoP and NiCoP-CNTs, respectively. The stability test of NiCoP-CNTs also shown the remarkable catalytic activity for long-term operation.
\end{abstract}

Keywords: NiCoP, bimetal phosphide, electrocatalyst, water oxidation

\section{$\underline{\text { FULL TEXT }}$}

(C) 2016 The Authors. Published by ESG (www.electrochemsci.org). This article is an open access article distributed under the terms and conditions of the Creative Commons Attribution license (http://creativecommons.org/licenses/by/4.0/). 